\title{
Analyzing ecological footprint of residential building construction in Adama City, Ethiopia
}

\author{
Dejene Tesema Bulti ${ }^{*}$ and Tibebu Assefa ${ }^{2}$
}

\begin{abstract}
Background: The pressure of urbanization on the earth's ecosystem is becoming unprecedented and urges a clear policy at all levels. Urbanization in Ethiopia is so swift that needs to balance its pace with resources the urban way of life need. For this, a residential neighborhood in Adama City is considered and checked for its sustainability using the ecological footprint (EF) method. Cluster analysis and regression analysis were used for grouping the sampled residences and relating EF with the combination of family size, floor area and plot area, respectively. Computing the biocapacity of the country, the level of resource consumption for residential building construction was compared and contrasted.

Result: The results show that from 1.084 to $8.146 \mathrm{gha} /$ capita resources were consumed and the overall EF is found to be $2.952 \mathrm{gha} /$ capita. The deficit is found to be $1.277 \mathrm{gha} / \mathrm{capita}$, indicates that the existing practice is not sustainable. Moreover, the significant relationship is found between the EF and the linear combination of floor area, family size and plot area. Besides, the EF is sensitive to the variability of floor area.

Conclusions: In line with the growing concern of sustainable urban growth, planners and stakeholders should recognize where there is over-utilization of natural capital and plan a new heading before negative outcomes become irreversible. Formulation of policies for sustainable resource use should also aim to create a balance between ecological and socio-economic needs.
\end{abstract}

Keywords: Residence, Footprint, Ecology, Biocapacity, Resource, Construction

\section{Introduction}

Although building industry is a vital component of any economy, it has significant impact on the entire environment by the way we design, construct and use of our buildings. At global level, buildings are responsible for $40 \%$ of all energy consumption, $45 \%$ of the raw materials flow in global economy every year (UNEP 2007) and $40 \%$ of solid waste generation in the cities (Yilmaz and Bakiş 2015). While the impacts of this trend are not always immediately apparent, their cumulative effect on resource depletion and biological diversity loss is

\footnotetext{
*Correspondence: dejenetesema@yahoo.com

${ }^{1}$ Department of Urban and Regional Planning, Ethiopian Institute of Architecture, Building Construction, and City Development, Addis Ababa University, Addis Ababa, Ethiopia

Full list of author information is available at the end of the article
}

undeniable. Particularly, residential buildings represent a large share of the built-environment (Umar et al. 2012), so unmaintainable resource use in their construction has detrimental effects on the general sustainability.

In response to these effects, naturally-ordered utilization can make significant contribution to ensure sustainable construction. Ecological sustainability needs consideration of the environmental values of natural resources in utilizing and managing them (Pearce and Vanegas 2002) since the time required for resource renewal hinges on available reserve and on yearly consumption (Miglietta and Pastore 2010). Under existing scenario of increased resource consumption and waste assimilation, understanding the level of resource utilization is important to ensure sustainable development. 
Several measures [such as Life Cycle Assessment (LCA), ecological footprint (EF) etc.] have been developed to evaluate the sustainability of resource consumption. The ecological footprint (EF) approach has appeared as one of the effective indicators of human demand on nature (Husain and Prakash 2018). The concept was first developed in 1996 by Mathis Wackernagel and William Rees (Wilson 2005). The EF approach allows to convert most energy and material flows into bioproductive land and sea area. Consequently, it enables to jointly measure the resource flows and available biocapacity (BC) required to maintain them (Wiedmann and Barrett 2010; Borucke et al. 2013; Lin et al. 2016). Both are measured in a standardized unit known as a global hectare (gha), and one global hectare is equivalent to one hectare of bioproductive land with world average productivity. Since its formulation, the concept of EF has been widely used in evaluation of several measures such as supply of the world's natural resources, the practicability of resource utilization, waste assimilation and general sustainability of a system (Husain and Prakash 2018).

In building sector, EF indicator has been used in sustainable decision-making. Airaksinen and Matilainen (2011) optimized energy consumption in design alternatives of new office building in Finland. Simion et al. (2013) also used the EF method to identify the most appropriate scenario of construction and demolition waste integrated management system in two European cities. Assessment of environmental impact is also another application area of EF. Lim et al. (2017) analyzed the carbon footprint of industrialized building system in Malaysia while Teng and Wu (2014) analyzed sustainability of exhibition hall in Hubei province, China.

In particular, some researchers have used EF approach to analyze sustainability of residential building construction. Bastianoni et al. (2006) compared the level of resource use in construction of two-story detached residential and multi-story condominium Italian buildings. Consequently, the resource use is found to be sustainable when compared with the available global and local $\mathrm{BC}$ whereas construction of detached residential building consumed relatively larger EF. On the other hand, Larralde et al. (2014) argued that lesser EF per square meter is required to construct the Spanish residences than the Mexican dwellings, whose household size is smaller. Evaluating dwelling construction projects in Spain, GonzálezVallejo et al. (2015) reported that the EF value per unit square meter of detached houses is significantly larger than that of four-floor multi-family buildings while it is constant for taller buildings. Moreover, Liu et al. (2018) evaluated sustainability EF of different typical rural residential houses in China and documented in their conference paper.
The above acknowledged studies have provided a good insight about the building dependence of resources. However, the studies are relied on statistical data and measurements from design that appears to be the cases of areas where data is well documented, so the potential of the EF in data-scarce environments is not well investigated. In addition, majority of the studies conducted on residential buildings are deliberated on comparative analysis between different buildings. As a result, there is only little information about the sustainability of the resource consumption with respect to local available ecological supply. Moreover, these studies have explained the level of resource consumption in residential building construction with respect to various variables such as type of buildings (detached or multi-family), number of floors (single or multi-story), geographical location, and household size. However, how the combined set of variables explains the EF has not been well understood.

Ethiopia is among the countries under rapid urbanization, but evaluating sustainability of resource utilization in construction is uncommon. Particularly, in Adama City, the extent of environmental pressure associated to resource consumption in construction of residences remains unknown. With respect to growing concern of sustainable urban growth, understanding whether the available natural capital of the country can support existing consumption pattern can provide a basis for setting goals and identifying options for action.

The central aim of this study is to analyze the sustainability of resource consumption in construction of detached residential buildings in Adama City using the EF approach. More specifically, the study is conducted (i) to compute EF of residential buildings; (ii) to evaluate the level of natural resource consumption against available local biocapacity and (iii) to explore the relationship between EF and the combination of family size, floor area, and plot area.

\section{Materials and methods The study area}

Adama City is one of the fast-growing cities in Ethiopia. It stretches between $8^{\circ} 26^{\prime} 15^{\prime \prime} \mathrm{N}$ to $8^{\circ} 37^{\prime} 00^{\prime \prime} \mathrm{N}$ latitude and $39^{\circ} 12^{\prime} 15^{\prime \prime} \mathrm{E}$ to $39^{\circ} 19^{\prime} 45^{\prime \prime} \mathrm{E}$ longitude. Using the data from statistical sources (ASTU 2016; Bulti and Sori 2017), the computed population growth rate of the City from 2004 to 2016 was nearly 9\%. The City has various advantages that make it an appropriate selection for this study. Among these, the study can provide important information for the ongoing revision project of the development plan of the City. In addition, it is located at easy to find data and verify and interpret the findings. Particularly, the selected neighborhood is located at northern part of the City (Fig. 1) and covers about 58 hectare of land. 


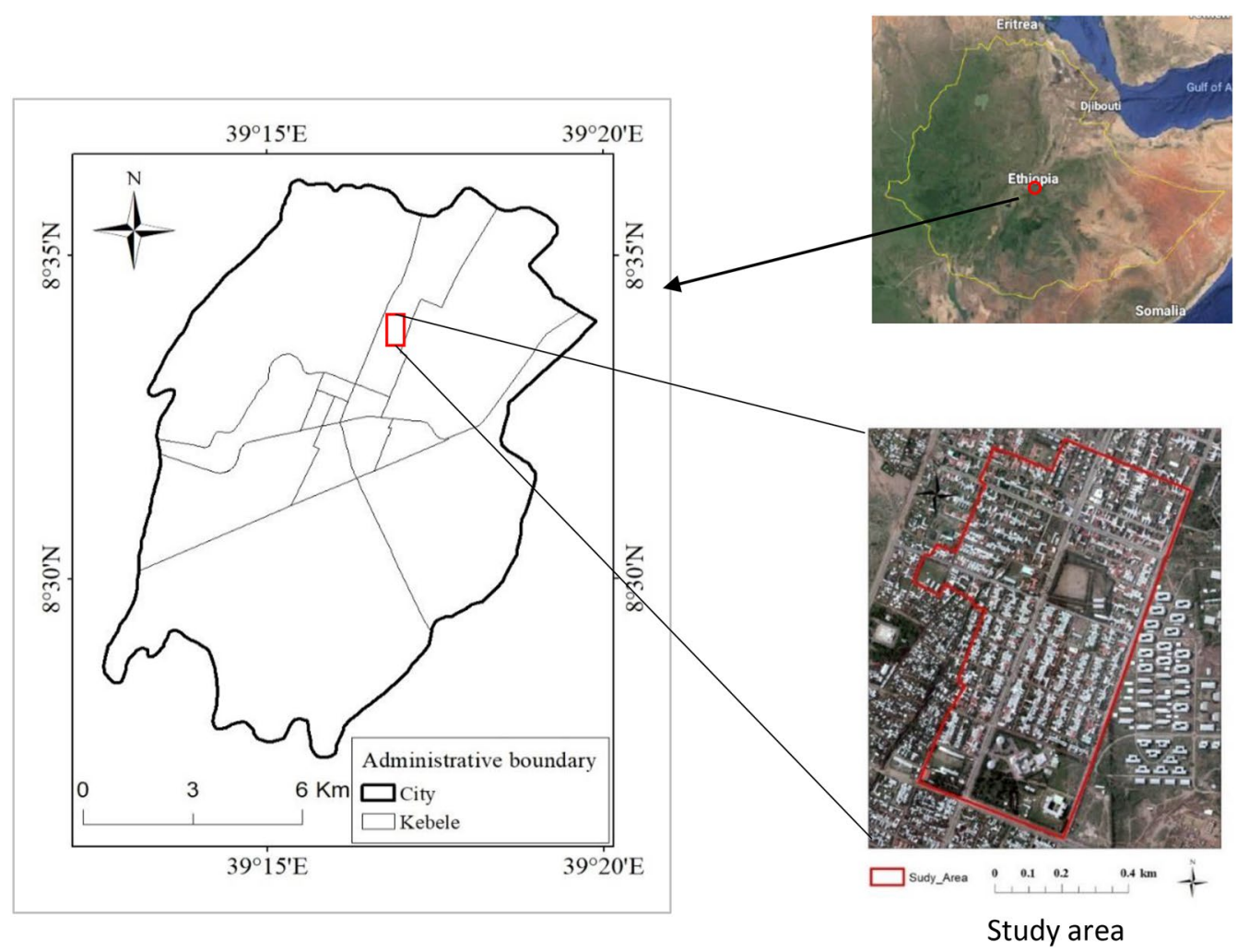

Fig. 1 Location map of the study area

The site encompasses discrete buildings which are ease to identify and take measurement. Moreover, the composition of the buildings represents major features of residential buildings being constructed in the City since 2010.

\section{Selection of sample residences}

The selected neighborhood comprises of 967 detached residential buildings with different variables including building type (forms), plot area and floor number (Appendix). The residences were grouped and number of appropriate groups was determined using cluster analysis in NCSS 12.0.6 statistical software. Nominal values (Appendix) were assigned for all variables in order to facilitate the computation of dissimilarity (distance) between objects in each cluster.

The dissimilarity was minimized using Medoid algorithm. Using silhouette values, the number of clusters was determined and the strength of clusters was assessed. The silhouette value indicates how well an object has been classified by comparing its dissimilarity within its cluster with that of in the other clusters; it ranges from -1 to 1 . The value close to 1 shows strong similarity of an object with objects within its cluster whereas -1 shows dissimilarity of an object with the objects of its cluster is higher than objects in the other clusters. In this regard, an appropriate number of clusters is the one that maximizes an average silhouette value. The strength of the structure in each cluster was determined using the maximum average silhouette value (SC) and the cut-off values proposed by Kaufman and Rousseeuw (1990). Finally, one plot was selected randomly from each of the resulted 11 clusters, and the descriptions of the sampled residences are shown in Table 1.

\section{Data and data acquisition}

Data used in this study were collected from different sources. Data of sampled residences including family size, types and sources of construction materials and actual measurements of building details were collected through field survey. As-built drawings of the buildings were prepared using actual measurements from which the quantities of construction materials were computed. In addition, sources of materials and transportation routes were identified on the map and travel distances were measured in GIS environment. The amount of consumed fuel was computed from travel distances and average fuel consumption of the trucks. The number of labors for the construction and proportion of waste were adopted from the literatures. 
Table 1 Descriptions of sampled residences

\begin{tabular}{|c|c|c|c|c|c|}
\hline Representative plot & Building type & No of floors & Plot area $\left(\mathrm{m}^{2}\right)$ & Floor area $\left(\mathrm{m}^{2}\right)$ & Family size \\
\hline $\mathrm{C} 1$ & Villa & 1 & 180 & 120 & 6 \\
\hline $\mathrm{C} 2$ & L-shaped & 1 & 160 & 102.8 & 7 \\
\hline C3 & Service & 1 & 200 & 44.6 & 4 \\
\hline C4 & L-shaped & 1 & 200 & 156.8 & 6 \\
\hline C5 & service & 1 & 160 & 50.2 & 4 \\
\hline C6 & Villa & 1 & 200 & 104 & 6 \\
\hline$C 7$ & villa & 1 & 320 & 189.7 & 9 \\
\hline $\mathrm{C} 8$ & L-shaped & 1 & 200 & 143.7 & 7 \\
\hline C9 & Multi-story & 3 & 200 & 264.9 & 7 \\
\hline $\mathrm{C} 10$ & Service & 1 & 400 & 93 & 7 \\
\hline C11 & Multi-story & 2 & 200 & 320 & 7 \\
\hline Sum & & & 2420 & 1589.7 & 70 \\
\hline
\end{tabular}

\section{Methods}

\section{Computation of EF}

The EF quantifies the required resources for construction of the buildings and the related activities occur in the biosphere in a specified year through consideration of technologies and resource management in the same year. The impacts of buildings are generated over building's lifecycle such as construction, maintenance and demolition phases (Yilmaz and Bakiş 2015). In this study, EF of the buildings was calculated for the construction and demolition phases. The former corresponds to the time until the building becomes ready for use whereas the latter represents the end of its life. Moreover, EF was computed for construction materials, fuel for transportation of materials, construction and demolition waste, $\mathrm{CO}_{2}$ emission, the actual occupied land and labors' food consumption. However, it should be noted here that electrical and sanitary works are not included.

The total EF was computed from two partial prints: energy land and cropland. The energy land EF measures bioproductive land required for maintenance of natural capital to replace the consumed energy by supplying a biomass substitute and additional capacity of the biosphere needed to uptake the $\mathrm{CO}_{2}$ emission. On the other hand, cropland EF measures the capacity required to substitute the actual occupied land and labors' food consumption. In this case, similar to (Monfreda et al. 2004), it is assumed that the human settlement, most often, occupies agricultural regions.

Biomass substitution $\left(E F_{b m}\right)$ calculates the area needed to replace fossil fuel with energy equivalent to fuelwood. Fuelwood is chosen as the default replacement since it is historically dominant fuel for most societies, and it is a primary fuel that the biosphere supplies without human modification (Wackernagel et al. 2005). In this regard, all construction materials, fuel for transportation and construction and demolition waste were converted to a common fossil fuel energy equivalent using the embodied energy of respective materials (Appendix). The sum of all energies (E) was used in the computation of EF of biomass substitution was computed using Eq. (1).

$$
E F_{b m}=\frac{E}{F Y * E P} * e_{f}
$$

E: total energy consumed (GJ), FY: forest yield (GJ/ha), $E F$ : forest expansion factor, $e_{f}$ : equivalence factor (gha/ ha).

Emission uptake $\left(\mathrm{EF}_{\mathrm{CO}_{2}}\right)$ embodied carbon of the construction materials was converted to equivalent $\mathrm{CO}_{2}$ using factor $(\mathrm{f}=0.27)$ adopted from Lin et al. (2016). Similar to Bastianoni et al. (2006), a factor of $0.020 \mathrm{~kg}$ of $\mathrm{CO}_{2}$ for each $\mathrm{MJ}$ of average fossil fuel was assumed. Moreover, energy expenses due to the use of natural products such as timber are assumed to be compensated by the absorption of $\mathrm{CO}_{2}$ through trees during their growth; hence, a hypothesis of a zero-emission factor has been considered for wood. Then, the biologically productive area needed to sequester $\mathrm{CO}_{2}$ through afforestation was computed using Eq. (2) adopted from Borucke et al. (2013).

$$
E F_{\mathrm{CO}_{2}}=P_{c} * \frac{\left(1-S_{\text {ocean }}\right)}{Y_{c}} * e_{f}
$$

$\mathrm{P}_{\mathrm{c}}$ : annual anthropogenic emissions carbon dioxide (ton), $\mathrm{S}_{\text {ocean }}$ : ocean uptake fraction, $\mathrm{Y}_{\mathrm{c}}$ : sequestration rate of world average forest land (ton/ha), $\mathrm{e}_{\mathrm{f}}$ : equivalence factor (gha/ha).

Cropland EF was computed for the plot area and labors' food consumption. EF of plot area was computed equal to that of cropland adjusted for its productivity using the yield factor (Eq. 3).

$$
E F_{B}=A * \frac{Y_{N}}{Y_{W}} * e_{f}
$$


$A$ : plot area consumed (ha/year), $e_{f}$ equivalence factor of built land (gha/ha), $\mathrm{Y}_{\mathrm{w}}$ : world cropland yield (ton/ha), $\mathrm{Y}_{\mathrm{N}}$ : computed national cropland yield (ton/ha) (Appendix).

In addition, a footprint of labors' food consumption was determined from total hours spent in the construction of the buildings. It was computed using Eq. (4) adopted from González-Vallejo et al. (2015).

$$
E F_{F}=\frac{E F_{m} * N_{w} * N_{w d}}{h_{m} * h_{w}}
$$

$E F_{m}$ : ecological footprint (gha/year/meal), $N_{w}$ : number of workers on the construction site, $N_{w d}$ : number of working days, $\mathrm{h}_{\mathrm{m}}$ : working hours per meal, $h_{w}$ : working hours per day.

Finally, the total EF of each sample is obtained from the sum of biomass substitution, emission uptake and cropland. Moreover, per capita, per floor area, and per plot area proportion were computed using the ratio of EF of each sample to respective variables. However, overall per capita consumption of EF was computed using the ratio of the sum of all EF of sampled plots to the sum of the family sizes of all residences.

\section{Computation of local biocapacity}

Biocapacity is the amount of biologically productive land and sea available to provide ecosystem services or regenerative capacity of nature (Borucke et al. 2013). In this study, biocapacity of the country was computed from the sum of available woody land and total crop productive land in the country as of 2014 using Eq. (5). The per capita available $\mathrm{BC}$ was computed by dividing the total biocapacity to the total population of the country as of the same year.

$$
B C=\sum_{i=1}^{n} A_{i} * Y_{i} * e_{i}
$$

$\mathrm{A}_{\mathrm{i}}$ : available bioproductive land (ha), $\mathrm{Y}_{\mathrm{i}}$ : national to world yield factor, $\mathrm{e}_{\mathrm{i}}$ : equivalence factor (gha/ha).

\section{Computation of Ecological sustainability of resource consumption}

Ecological sustainability analysis was conducted to determine whether the local natural capital is sufficient to support the resource consumption pattern. The balanced demand (EF) and supply capacity (BC) explains that the consumption is associated with the natural capacity of the country to recover after the stress generated by human activities (Simion et al. 2013). The disparity between the amount of resource consumed and the available supply capacity indicates the level of ecological sustainability (Moore et al. 2013). In this study, it was computed using the per capita proportion of demand and supply capacity (Eq. 6).

level of ecological sustainablity $(e)$

$=(B C /$ capita $)-($ EF $/$ capita $)$

If, $e<0$, ecological deficit; $e>0$, ecological reserve.

\section{Statistical modelling}

Statistical modelling in this study refers to a statistical approximation intended to reflect the underlying structure of a data generating process. It is carried out to determine how well the computed EF can be explained by the linear combination of floor area of the buildings, family size and plot area. In this context, regressionbased technique was used to explore the linear relationship of response and the three explanatory variables. It is the commonly used method to investigate the relationship between a quantitative outcome and quantitative explanatory variables (Seltman 2018).

The data set of computed EF and independent variables of the sampled plots was used in the multiple regression analysis which is carried out using SPSS statistical software. Regression parameters were estimated using the method of least squares. This method fits the model to the observed data by minimizing the sum of the squares of the deviations of the theoretical data points from the observations.

The goodness-of-fit of the model was assessed through investigation of the agreement between observed values and predicted values of EF. This approach provides important information on the quality of the fit of the linear model to the observed data in both simple and multiple regression (Rawlings et al. 1998; Chattefuee and Hadi 2006). With a good fit, the two sets of data close to each other. In this study, the goodness-of-fit was evaluated using the values of correlation coefficient and coefficient of determination.

The validity of the model assumptions was determined by examining the structure of the residuals and the data pattern through graphs. Examination of residual plots is a simple and effective method for validation of standard assumptions in regression analysis (Chattefuee and Hadi 2006). In this context, the normality assumption was validated using normal probability plot of standardized residuals which is a plot of the ordered standardized residuals against the normal scores. Under normality assumptions, this plot should resemble a (nearly) straight line with an intercept of zero and a slope of one, and they are equal to mean and standard deviation of the standardized residuals, respectively. In addition, scatter plots of the standardized residual against each of the predictor variables and fitted values were used to validate the linearity assumption. Under the standard assumptions, the 
standardized residuals are uncorrelated with each of the predictor variables and with fitted values. The random scatter of points of these plots explains the validity of linearity assumption.

The strength of the linear relationship between response and a set of predictor variables was determined from the value of the multiple correlation coefficient $(R)$. The non-zero value was described using the guide that Evans (1996) suggests for absolute value of correlation coefficient: very weak $(|R|<0.19)$, weak $(|R|<0.39)$, moderate $(|R|<0.59)$, strong $(|R|<0.79)$, very strong $(|R|<1)$. Moreover, statistical significance test was conducted to offer an objective measure in the decision about the validity of the generalization, and it was determined using p-value statistics. In theory, the p-value is a continuous measure of evidence (Gelman 2012), yet in this study, the term "significant" refers to the $95 \%$ confidence level $(\mathrm{p}<0.05)$; it is standard in statistical practice in most of the Engineering researches.

Sensitivity analysis was conducted to identify the model variable whose variability strongly influences model's response. Standardized coefficient of a linear regression model is useful measure of sensitivity analysis (Saltelli et al. 1993; Hamby 1994); especially, when the independent variables are measured in different units (Nieminen et al. 2013). In this regard, the model is more sensitive to the parameter that has larger magnitude of standardized regression coefficient (Saltelli et al. 2000), and it was employed in this study to determine the relative importance of explanatory variables.

In general, the overall procedures used in this study is depicted in Fig. 2.

\section{Results}

\section{$\mathrm{EF}$ of the buildings}

The computed values of EF using Eqs. 1 to 4 "Methods" are summarized in Table 2. The sampled plots are arranged in column while EF values are organized in rows. The EF of sampled residences are the result of the sum of partial prints categorized as: (i) forest land required for biomass substitution and waste accommodation, and (ii) cropland required to substitute land for

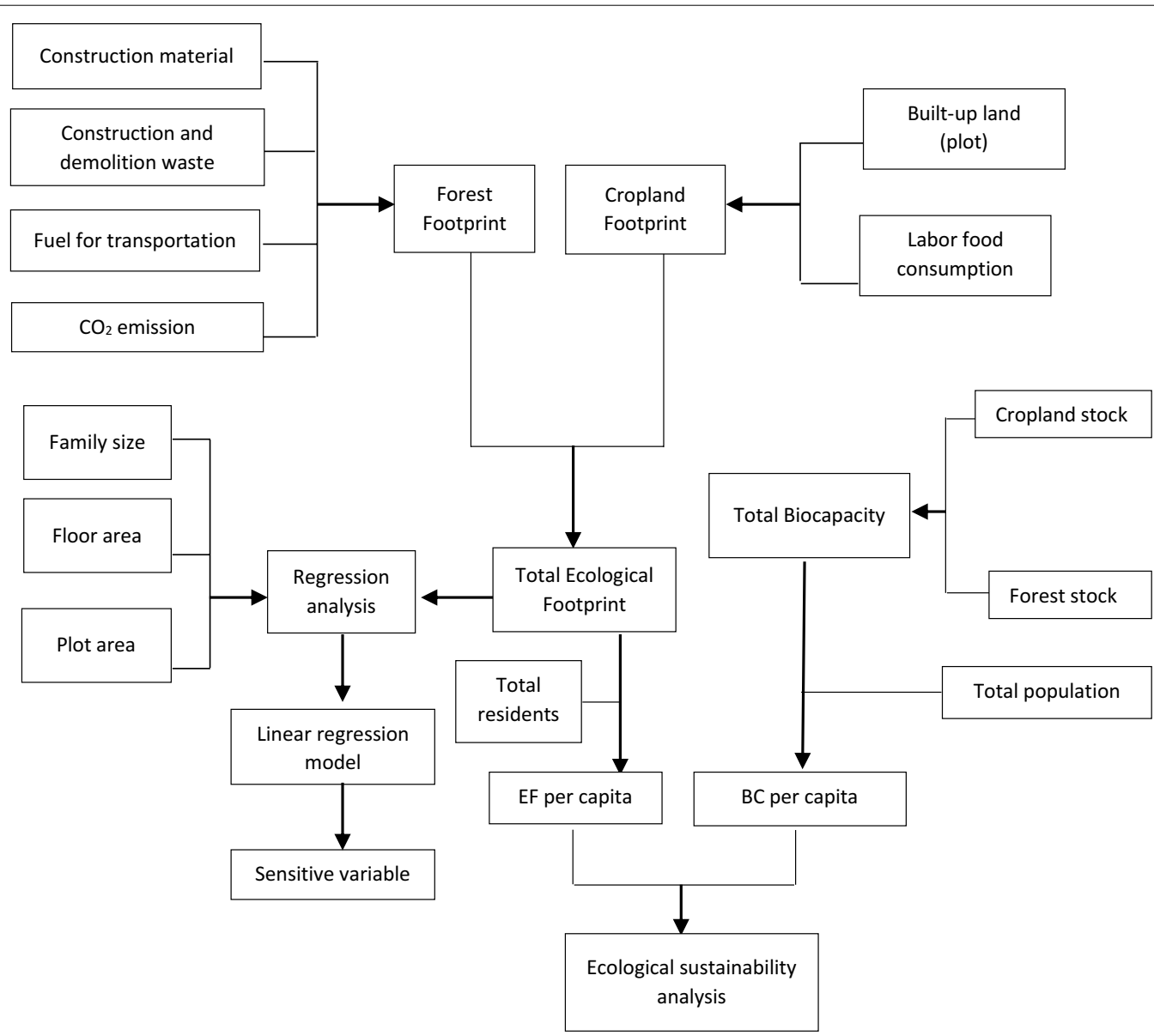

Fig. 2 General workflow of the study 
Table 2 Ecological footprint of buildings on sampled plots (gha)

\begin{tabular}{|c|c|c|c|c|c|c|c|c|c|c|c|c|}
\hline & $\mathrm{C} 1$ & $\mathrm{C} 2$ & C3 & $\mathrm{C} 4$ & $\mathrm{C5}$ & $\mathrm{C} 6$ & $\mathrm{C7}$ & $\mathrm{C} 8$ & $\mathrm{C} 9$ & C10 & C11 & Total \\
\hline \multicolumn{13}{|l|}{ Forest } \\
\hline Material & 6.557 & 6.755 & 2.381 & 7.140 & 2.079 & 5.916 & 7.311 & 7.525 & 26.045 & 4.070 & 30.418 & 106.197 \\
\hline Fuel & 0.282 & 0.187 & 0.122 & 0.201 & 0.122 & 0.273 & 0.354 & 0.215 & 0.400 & 0.171 & 0.600 & 2.927 \\
\hline C and DW & 5.913 & 6.593 & 1.985 & 6.998 & 1.985 & 5.744 & 7.232 & 7.403 & 21.298 & 3.973 & 25.579 & 94.703 \\
\hline $\mathrm{CO}_{2}$ emission & 0.034 & 0.035 & 0.013 & 0.037 & 0.013 & 0.033 & 0.043 & 0.040 & 0.094 & 0.024 & 0.120 & 0.486 \\
\hline \multicolumn{13}{|l|}{ Cropland } \\
\hline Plot of land & 0.071 & 0.071 & 0.089 & 0.080 & 0.071 & 0.089 & 0.089 & 0.089 & 0.089 & 0.178 & 0.089 & 1.005 \\
\hline Labor food & 0.106 & 0.114 & 0.065 & 0.117 & 0.065 & 0.104 & 0.120 & 0.120 & 0.178 & 0.088 & 0.219 & 1.296 \\
\hline Total EF/plot & 12.964 & 13.756 & 4.655 & 14.574 & 4.336 & 12.159 & 15.150 & 15.391 & 48.103 & 8.505 & 57.024 & 206.6 \\
\hline EF/capita & 2.161 & 1.965 & 1.164 & 2.429 & 1.084 & 2.027 & 1.683 & 2.199 & 6.872 & 1.215 & 8.146 & \\
\hline $\mathrm{EF} / \mathrm{m}^{2}$ (floor area) & 0.11 & 0.13 & 0.10 & 0.09 & 0.09 & 0.12 & 0.08 & 0.11 & 0.18 & 0.09 & 0.18 & \\
\hline $\mathrm{EF} / \mathrm{m}^{2}$ (plot area) & 0.07 & 0.09 & 0.02 & 0.07 & 0.03 & 0.06 & 0.05 & 0.08 & 0.24 & 0.02 & 0.29 & \\
\hline
\end{tabular}

Overall computed ecological footprint: $\mathrm{EF} / \mathrm{capita}=2.952, \mathrm{EF} / \mathrm{m}^{2}$ of floor area $=0.130, \mathrm{EF} / \mathrm{m}^{2}$ of plot area $=0.083$

actual occupation as well as labor food consumption. The graph depicted in Fig. 3 also demonstrates the relative variation in resource consumption for construction of sampled residences.

Overall, the EF values across the samples ranges from 4.366 to 57.024 gha. In addition, the averages of resource consumption computed by the ratio of the total EF (206.6 ha) to the total number of residents, total floor area and plot area are 2.952 gha/capita, 0.13 gha $/ \mathrm{m}^{2}$ and $0.085 \mathrm{gha} / \mathrm{m}^{2}$, respectively.

In terms of partial prints, about $50 \%$ of the total $E F$ is related to construction materials followed by construction and demolition waste. This due to consideration of all stock material as demolition waste except that of wood since there is no recycling practice in existing waste management trend of the City. On the other hand, the actual occupation of the plot of land is associated with least partial print. Surprisingly, more than half of the total EF is due to buildings on a couple of plots (C11 and C9) with multi-story buildings of 2 and 3 floors.

Further, the findings demonstrate the significant EF differences between per capita resource consumption ranging from $1.084 \mathrm{gha} /$ capita to $8.146 \mathrm{gha} / \mathrm{capita}$, and they are related to plots $\mathrm{C} 5$ and $\mathrm{C} 11$, respectively. These plots are holding the first and the last positions in terms of total EF per plot shows at least the family size did not influence the result of EF in the case of the two ends. On the other hand, the minimum proportion per unit floor area is related to $\mathrm{C}$, and in terms of the per unit plot area, the least value is associated with $\mathrm{C} 3$ and $\mathrm{C} 10$.

\section{Sustainability analysis}

The calculated available woody land as of 2014 is 34.136 million hectares and that of cropland computed as the

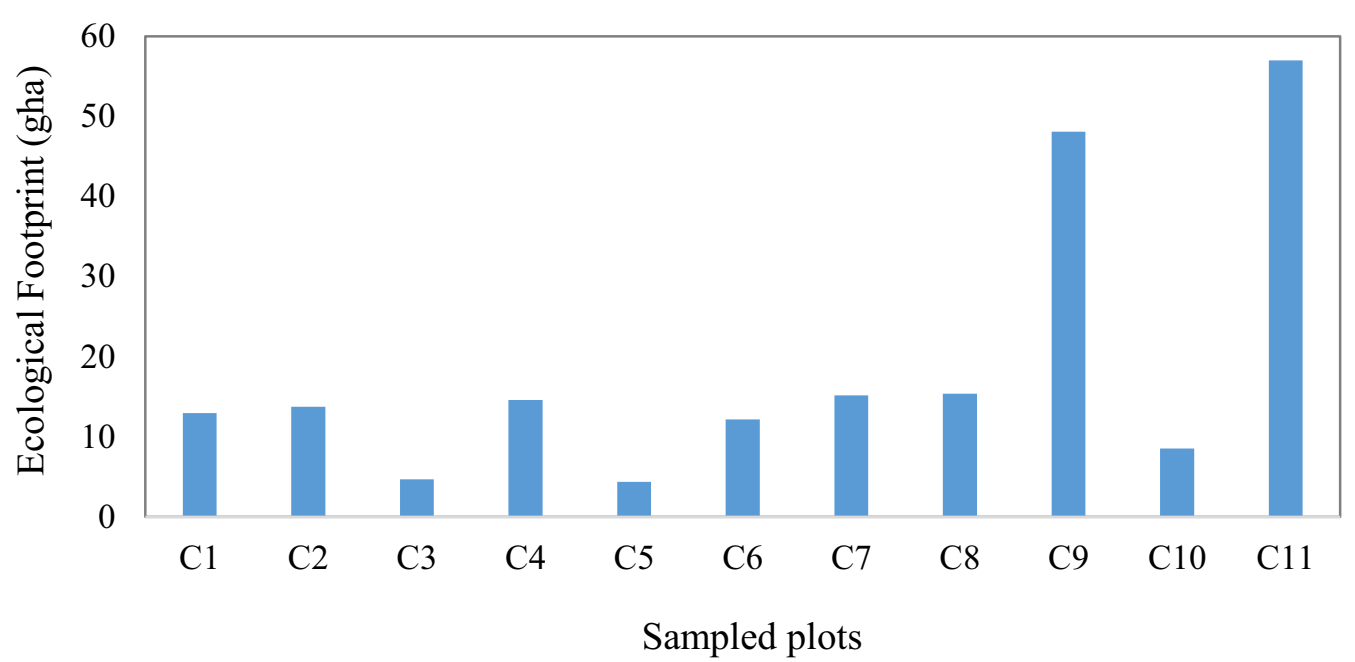

Fig. 3 Ecological footprint of residences on the sampled plots 
sum of crop productive land areas in the country is 26.443 million hectares. Using these as input in addition to respective yield factors and equivalent factors, Eq. (5) results biocapacity potential of the country as of the year is found to be 161.618 million gha. The per capita available biocapacity obtained by the total bioproductive land divided by the total population of the country as of the year ( 96.5 million) is found to be 1.675 gha/capita.

Using Eq. (6), comparison of per capita biocapacity with EF per person (2.952 gha/capita), the overall ecological difference results in $1.277 \mathrm{gha} /$ capita showing an ecological deficit. Further, the result depicted in Fig. 4 demonstrates the significant variation in the level of sustainability in resource consumption ranges from 0.58 to -6.485 gha/capita. An ecological reserve (positive ecological difference) is obtained for buildings on three plots out of eleven (about $27 \%$ of the sample) while in the case of the rest eight sampled plots ecological deficit (negative ecological difference) is obtained. The minimum and maximum deficit are associated with plots $\mathrm{C} 7$ and $\mathrm{C} 11$, respectively. Moreover, the deficit related to buildings on plot C9 and C11 is significantly greater than that of the others indicates the multi-story buildings might have a large share in contributing to the overall ecological deficit.

\section{Regression analysis}

The regression analysis conducted in this study aims at describing the relationship between response variable (EF) and the linear combination of explanatory variables: floor area, family size and plot area. The data used in the model fitting consists of eleven observations of sampled plots: response variable from Table 2 and explanatory variables from Table 1 . The mean and standard deviation of the observations are EF $(M=18.78, S D=17.27)$, floor area $(M=144.52, S D=85.44)$, family size $(M=6.36$, $S D=1.43)$, and plot area $(M=220, S D=73.21)$.

In fitting the model, regression parameters are estimated using method of least squares that minimizes the sum of the squared deviations between the theoretical data points and the observations. Table 3 shows the output of regression analysis. The estimated regression equation of the fitted full model that relates the variables is shown in Eq. (7).

$$
\begin{aligned}
E F= & 7.395+0.222 *(\text { Floor_area })-3.127 \\
& *(\text { Family_size })-0.004 *(\text { Plot_area })
\end{aligned}
$$

The quality of the fit is assessed through examination of the agreement between the observed values of response variable in the data set and their corresponding values computed using the regression equation $(\mathrm{Mean}=18.783$,

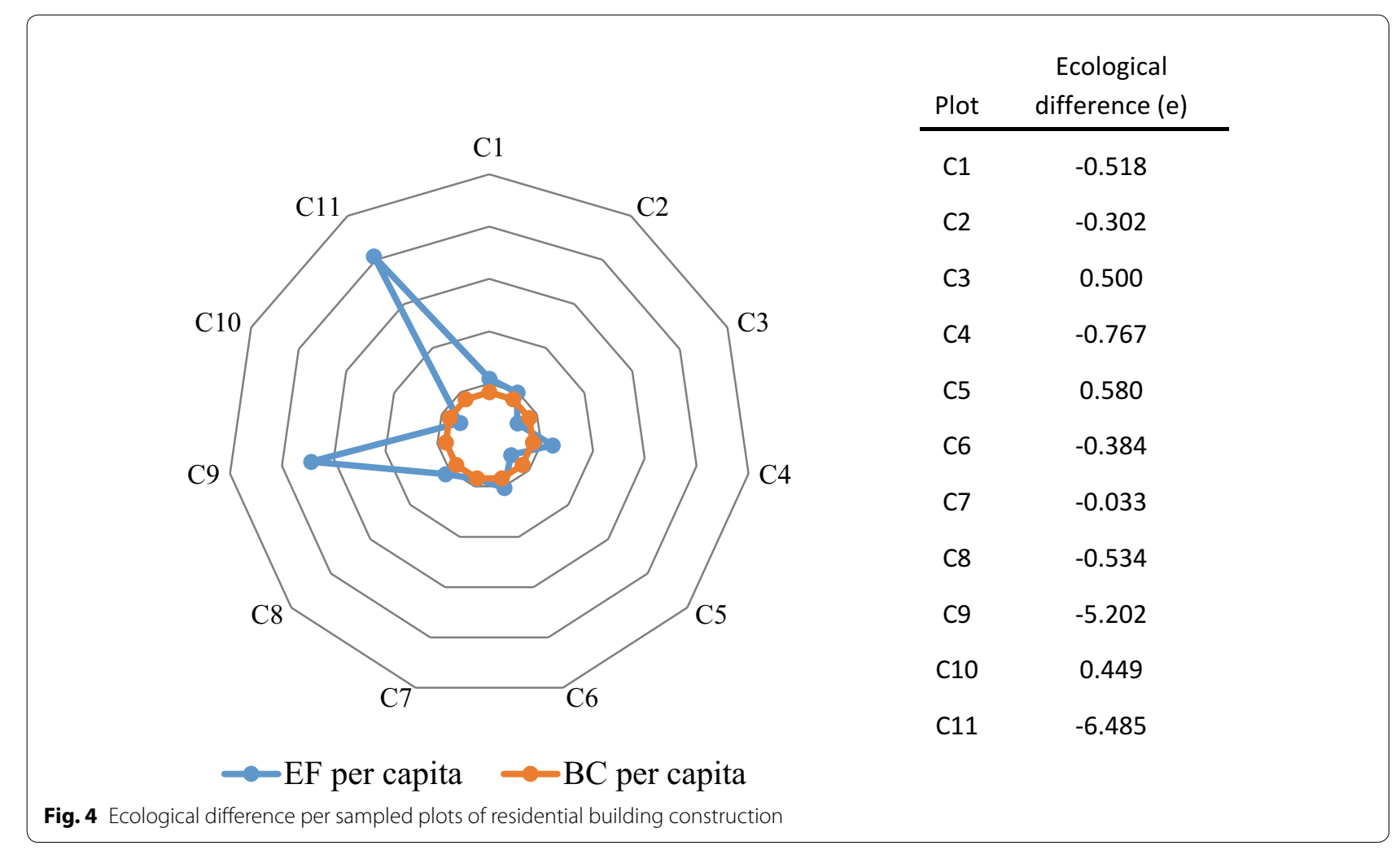


Table 3 The output of linear regression of response variable (EF) and three explanatory variables

\begin{tabular}{|c|c|c|c|c|c|c|c|}
\hline \multirow[t]{2}{*}{ Variable } & \multicolumn{2}{|c|}{ Unstandardized coefficient } & \multirow{2}{*}{$\begin{array}{l}\text { Standardized } \\
\text { coefficient }\end{array}$} & \multirow[t]{2}{*}{ t-Stat } & \multirow[t]{2}{*}{ p-value } & \multicolumn{2}{|c|}{$95 \%$ confidence interval } \\
\hline & Coefficients & Std. error & & & & Lower & Upper \\
\hline Constant & 7.395 & 7.3836 & & 1.002 & 0.34994 & -10.064 & 24.855 \\
\hline Floor area & 0.222 & 0.0248 & 1.100 & 8.971 & 0.00004 & 0.164 & 0.281 \\
\hline Family size & -3.127 & 1.7001 & -0.260 & -1.839 & 0.10844 & -7.147 & 0.893 \\
\hline Plot area & -0.004 & 0.0268 & -0.016 & -0.142 & 0.89133 & -0.067 & 0.060 \\
\hline$n=11$ & & $R=0.971$ & & $R^{2}=0.942$ & & & \\
\hline
\end{tabular}

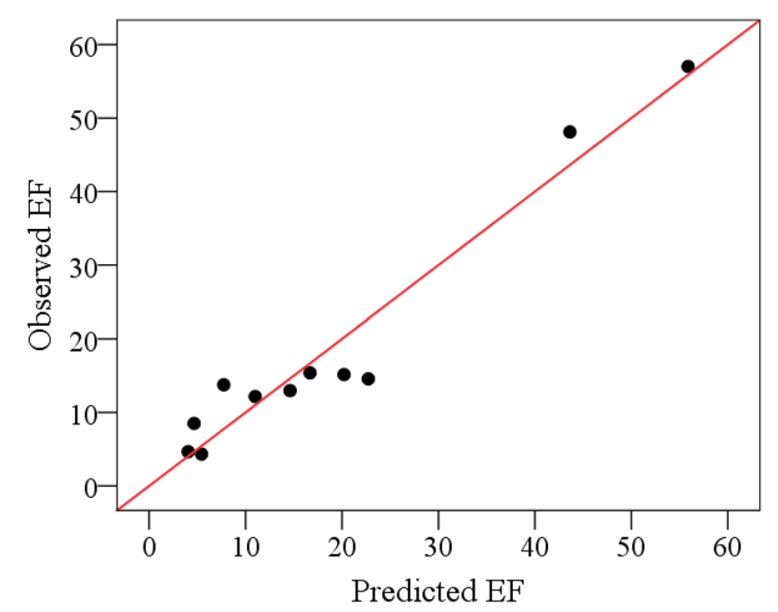

Fig. 5 Scatter plot of observed EF versus predicted EF overlaid with best fit linear regression line

Standard deviation $=16.762$ ). Figure 5, the plot of predicted EF versus the observed EF and overlaid with the best-fit regression line, provides a visual check on the agreement of the two sets of values. In addition, the closeness of points to the regression line and the result of correlation coefficient, $r=0.971, p<0.001$, demonstrates the significant correlation between the sets. The strong linear relationship between observed and predicted values of response variable in multiple linear regression analysis confirms the quality of the model to fit the data set of response and explanatory variables (Chattefuee and Hadi 2006). Likewise, the full regression model fitted in this study agrees with the actual data set.

The residual analysis was carried out to validate the model assumption. In this regard, the values of the mean and the standard deviation of standardized residuals are found to be 0.0 and 0.84 , respectively, indicate the normal distribution of residuals. In addition, the plots of standardized residual against the fitted values and independent variables depicted in Fig. 6 . The random scattered points in the plots demonstrate that the standardized residuals are uncorrelated with any of predictor variables as well as fitted values of response variable. Thus, the results of residual analysis validate the linearity and normality assumptions in the model.

Further analysis of significance test in terms of individual regression coefficients, the result in Table 3 shows that only the regression coefficient of floor area is significantly different from zero, and the other variables have insignificant t-tests. However, when the independent variables taken collectively, the result of significance test $\left(\mathrm{R}^{2}=0.942\right.$, $\left.\mathrm{F}(3,7)=38.2, \mathrm{p}<0.001\right)$ reveals that the observed linear relationship between response and a set of explanatory variables is statistically significant. Accordingly, $94.2 \%$ of the total variability in EF can be associated with the set of combined variation in floor area, family size, and plot area. Hence, the results confirm that the ecological footprint of detached residential building construction in the study area significantly related with linear combination of floor area of the buildings, family size, and plot area. Moreover, estimated regression equation of the full model (Eq. 7) adequately describes the linear relationship between EF and the composite explanatory variables.

\section{Sensitivity analysis}

Sensitivity analysis is conducted to identify the model variable whose uncertainty and variability strongly influence the model response. In this regard, a sensitive variable is investigated using simple and multiple linear regression. The result of multiple regression analysis (Table 3) in this study shows that the standardized coefficients of floor area, family size, and plot area are $1.1,-0.260$, and -0.016 , respectively. According to the proposal of Saltelli et al. (2000), the values suggest that the full fitted model is most sensitive to uncertainty and variability of floor area of the buildings whereas plot area is identified to be least sensitive variable. Further, the result indicates that the unit change in standard deviation of floor area changes the standard deviation of EF by the 1.1. In addition, the value is significantly different from zero indicates there is association between the floor area and EF, and the positive value of the lower limit of confidence interval indicates that the association is statistically significant. 


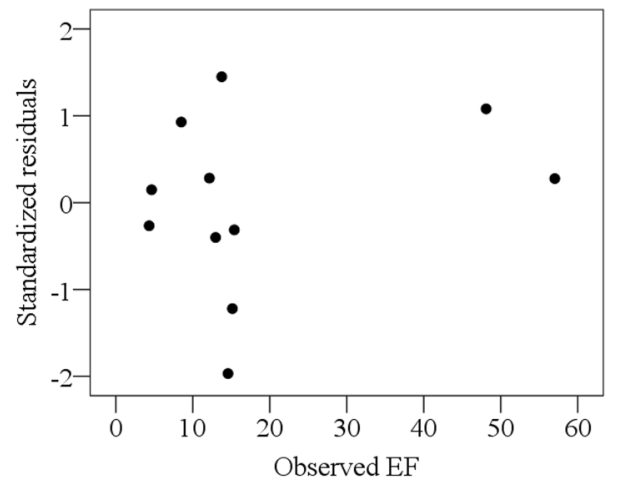

a Standardized residuals versus observed EF

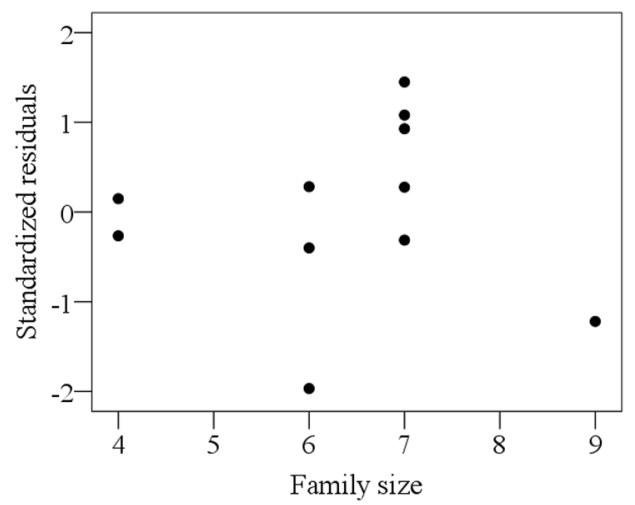

C Standardized residuals versus family size

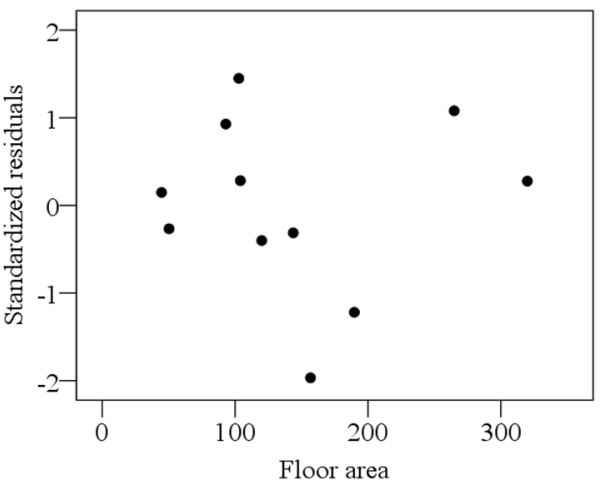

b Standardized residuals versus floor area

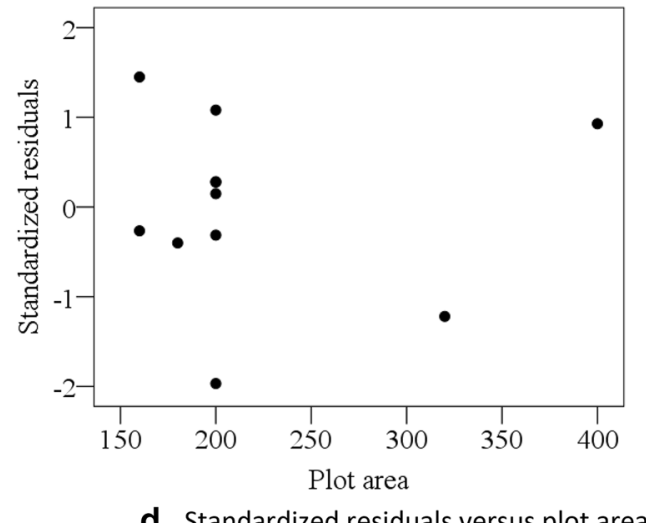

d Standardized residuals versus plot area

Fig. 6 Standardized residuals plotted against the predicted values (a) and each of the three independent variables (b-d)

In addition, the result of simple regression analysis is shown in the scatter plots of EF versus each of independent variables depicted in Fig. 7 and statistical results are summarized in Table 4. The value of Pearson correlation coefficient indicates a very strong significant correlation between EF and floor area, $r=0.946, p<0.001$. The value of $r^{2}=0.8944$ suggests nearly $90 \%$ of the total variability in the EF is accounted for by the floor area keeping other variables constant. In the contrary, the relationship is found to be not significant in the case with family size $(\mathrm{r}=0.38, \mathrm{p}=\mathrm{n} . \mathrm{s})$ and plot area $(\mathrm{r}=-0.13, \mathrm{p}=\mathrm{n} . \mathrm{s})$.

From these pieces of evidence, it can be concluded that the fitted regression model explaining the linear relationship of EF with the three predictor variables is more sensitive to the uncertainty and variability of the floor area of the buildings.

\section{Discussion}

From the objective aspect, this study is aimed at analyzing the sustainability of resource consumption in construction of detached residential buildings in Adama City using the EF approach. The bottom-up approach was used to determine the EF of selected residential neighborhood. The sampled residences were grouped using cluster analysis technique; actual measurements of buildings were taken; ecological footprint of residences are computed in terms of per capita efficiency and space efficiency. Available ecological supply capacity of the country was computed for the same year, and it was compared with EF to determine sustainability of resource use. Moreover, the relation EF with combined set of family size, plot area, and floor area was explored using linear regression analysis.

The result of EF computation demonstrates that every resident of the selected neighborhood has constructed his/her shelter at the cost of 2.429 hectare of global average bioproductive land. The result is significantly less than the value reported by González-Vallejo et al. (2015) for construction of dwellings in Spain, but it is slightly greater than that of Bastianoni et al. (2006) pertaining to two-story detached Italian residential buildings (0.122 gha/capita). In terms of space efficiency, the value of $E F$ is found to be $0.130 \mathrm{gha} / \mathrm{m}^{2}$, and it is moderately larger than that of two-story detached residential building in Italy found by Bastianoni et al. (2006). 


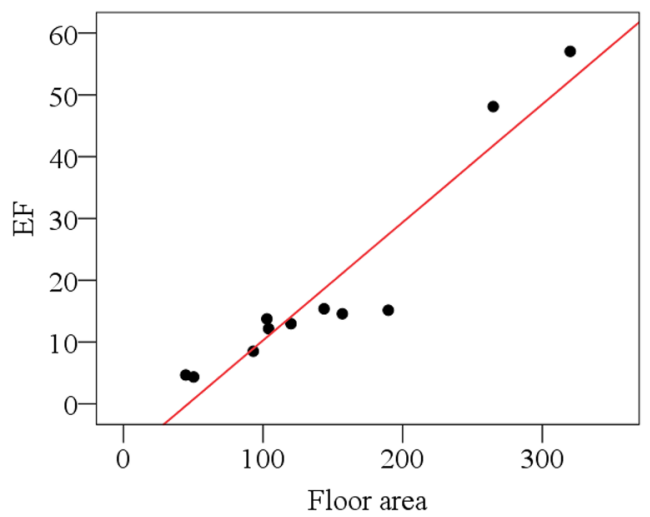

a Relationship of EF and floor area

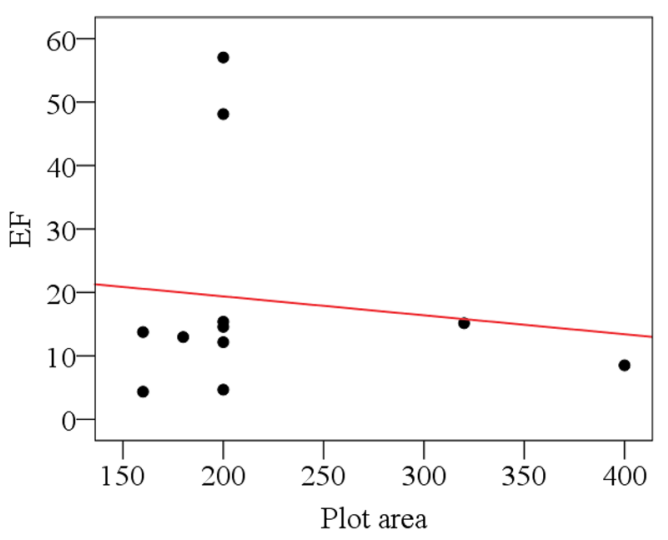

c Relationship of EF and plot area

Fig. 7 Scatter plot of EF against the three explanatory variables floor area (a), family size (b), plot area (c) and overlaid with best fit regression line

Table 4 Result of simple regression analysis of EF on the three predictor variables

\begin{tabular}{lrcrrr}
\hline Variable & Constant & Coefficient & \multicolumn{1}{l}{$\mathbf{r}^{\mathbf{2}}$} & $\mathbf{p}$-value \\
\hline Floor area & -8.838 & 0.191 & 0.9457 & 0.8944 & $<0.0001$ \\
Family size & -10.676 & 4.629 & 0.3843 & 0.1477 & 0.2432 \\
Plot area & 25.335 & -0.030 & -0.1263 & 0.0159 & 0.7114 \\
\hline
\end{tabular}

However, it is moderately less than that of the residential buildings in Spain (González-Vallejo et al. 2015) and in Mexico (Larralde et al. 2014).

The relative smaller EF value obtained in the present study may be attributed to its scope. The value will possibly increase with additional scope through consideration of maintenance phase and electrical and sanitary works. In addition, it is regarded that the trend of resource consumption in construction of buildings can be influenced by local situation such as social, environmental, cultural, and economic characteristics of the area (UNEP 2007). The result of this study is pertaining to the average of

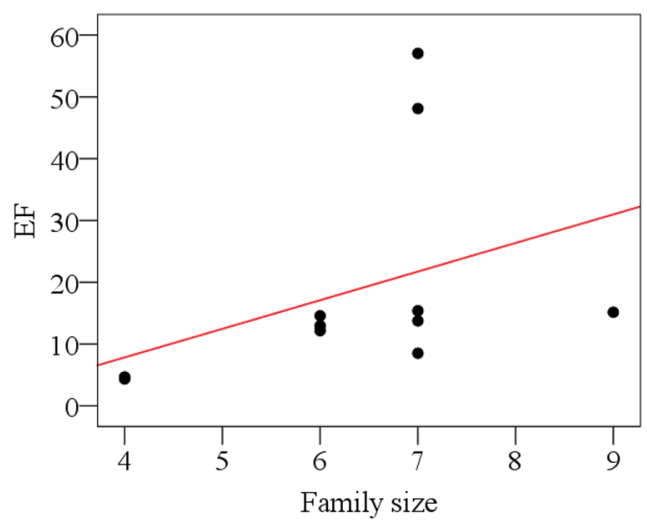

b Relationship of EF and family size analyzed sampled residences, and it is applicable to analyze the EF of residential building construction in Adama City.

The bottom-up approach used in this study has enabled to determine the EF of the residences and indicates the possible application of EF method in data-scarce environments. It has been noted that unavailability of data at local level is one of the most contributing factors to limited applications of the ecological footprint (Miglietta and Pastore 2010). Moreover, the result of EF can be an important information for planners and decision-makers of the City to recognize where there is over-utilization of resources and plan a new heading before negative outcomes become irreversible.

The level of sustainability of resource use is another important finding of this study. The result indicates that the existing practice of detached residential building construction is not sustainable as compared to local ecological supply capacity. The deficit is found to be 1.277 gha/ capita. Unmaintainable pattern of resource use with local ecological supply explains that the City is importing 
biocapacity through trade or liquidating regional ecological assets, or emitting wastes into the atmosphere. The observed level could be due to the absence of appropriate guideline to support sustainable resource use. In Adama City, the standards set in urban plan are deliberated on ensuring minimum criteria such as building area ratio and height regulation whereas the criteria to guide the resource consumption is lacking. Consequently, the developers are free to adopt any design as far as it meets minimum standard. In this case, the construction depends on the interest and economic potential of developers regardless of the type and the amount of resources to be used which can lead to over-utilization of natural capital.

The result of sustainability obtained in this study is different from that of the study by Bastianoni et al. (2006) in which sustainable resource use was reported for construction of two-story detached residential and multistory condominium Italian buildings. The variation may be: on top of the above mentioned limitation, worldwide resource distribution is uneven, and an average bioproductivity of a particular land use varies between countries (Borucke et al. 2013). The result of this study is referring to residential building construction in Adama City as compared to ecological supply capacity of Ethiopia as of 2014. The result could be used as spring board to enhance the construction and planning practice to ensure a balance between ecological supply and resource utilization. Moreover, the study indicates that analysis of sustainability of resource consumption with respect to the local available potential can provide a better understanding to formulate effective solution.

Modeling the relationship between EF and combination of the explanatory variables is another contribution of this study. The result confirms that the ecological footprint of detached residential building construction in the Adama City has significant relationship with linear combination of floor area, family size, and plot area. Moreover, the fitted regression model is found more sensitive to the uncertainty and variability of the floor area of the buildings. Despite it provides important information, the result can only be used as a baseline for further studies such as investigation of the cause and effect relationship with additional important variables.

\section{Conclusions}

In this study, the ecological footprint of detached residential building construction in Adama City as of 2014 is analyzed. The result reveals that a significant amount of resource has been consumed ranging from 1.084 to 8.146 gha/capita. In addition, overall EF of residential construction in the City is found to be 2.952 gha/ capita. Further, the overall resource consumption shows $1.277 \mathrm{gha} / \mathrm{capita}$ ecological deficit, indicating the existing practice is not sustainable. Moreover, EF of the residences have strong relation with the linear combination of floor area, family size, and plot area. Besides, it is sensitive to the variability of the floor area.

In line with the increasing concern of sustainable urban growth, the findings can help planners to recognize where there is over-utilization of resources and plan a new heading before negative outcomes become irreversible. Moreover, it can support formulation of effective development policies create a balance between ecological supply and resource consumption.

Despite it provide important information, this study should be considered only as an initial step towards understanding the links between resource consumption and residential building construction in Adama City. Future researches are needed with consideration of maintenance phase. In addition, investigation of cause and effect relationship between EF and the variables is also required. Moreover, studies in different urban centers of the country can increase understanding of resource consumption of the nation and support formulation of effective policies to the context.

\section{Abbreviations \\ BC: biocapacity; EF: ecological footprint.}

\section{Authors' contributions}

DTB has conceived of the study and made contributions in design, data collection, analysis, interpretation of results and draft the manuscript. TA has participated in the sequence alignment and critical commenting of the manuscript. Both authors read and approved the manuscript.

\section{Author details}

${ }_{1}^{1}$ Department of Urban and Regional Planning, Ethiopian Institute of Architecture, Building Construction, and City Development, Addis Ababa University, Addis Ababa, Ethiopia. ${ }^{2}$ Department of Urban Design, Ethiopian Institute of Architecture, Building Construction, and City Development, Addis Ababa University, Addis Ababa, Ethiopia.

\section{Acknowledgements}

We would like to thank the anonymous reviewers and the editor for their genuine comments and corrections which helps the paper to be in its present form.

Competing interests

The authors declare that they have no competing interests.

Availability of data and materials Not applicable.

\section{Consent for publication}

We have agreed to submit for Environmental Systems Research journal and approved the manuscript for submission.

Ethics approval and consent to participate Not applicable.

Funding

No funding was received. 


\section{Appendix}

See Tables 5, 6, 7, 8.

Table 5 Nominal values assigned for variables

\begin{tabular}{|c|c|c|c|c|c|}
\hline \multicolumn{2}{|l|}{ Typology } & \multicolumn{2}{|l|}{ Height } & \multicolumn{2}{|c|}{ Plot size $\left(\mathrm{m}^{2}\right)$} \\
\hline Existing & New value & Existing & New value & Existing & New value \\
\hline Service quarter & 0 & $G+0$ & 0 & 160 & 0 \\
\hline Villa & 1 & $G+1$ & 1 & 180 & 1 \\
\hline L-shaped & 2 & $G+2$ & 2 & 200 & 2 \\
\hline \multirow[t]{3}{*}{ High rise } & 3 & $G+3$ & 3 & 320 & 3 \\
\hline & & & & 400 & 4 \\
\hline & & & & 500 & 5 \\
\hline
\end{tabular}

Table 6 Number of points clustered under each clusters with the strength of their structures

\begin{tabular}{llll}
\hline Cluster No & No of objects (points) & Cluster average silhouette value (SC) & Strength of structure \\
\hline 1 & 33 & 0.5086 & Reasonable \\
2 & 22 & 0.5498 & Reasonable \\
3 & 9 & 1.0000 & Strong \\
4 & 32 & 0.5496 & Reasonable \\
5 & 36 & 0.9444 & Strong \\
6 & 97 & 1.0000 & Strong \\
7 & 20 & 1.0000 & Strong \\
8 & 296 & 1.0000 & Strong \\
9 & 14 & 1.0000 & Strong \\
10 & 107 & 1.0000 & Strong \\
11 & 301 & 1.0000 & Strong \\
Total & 967 & & 0.9687 \\
Overall average & & &
\end{tabular}

Table 7 Embodied energy and carbon of construction materials

\begin{tabular}{llll}
\hline Material & Embodied energy: MJ/kg & Embodied carbon: C/kg & References \\
\hline Cement & 5.9 & 0.248 & Hammond and Jones (2008) \\
Sand & 0.1 & 0.007 & Baird et al. (1997); Alcorn (2003) \\
Aggregate (rock) & 0.06 & 0.003 & Alcorn (2003) \\
Bar and rod & 24.6 & 0.466 & Hammond and Jones (2008) \\
Stone (general) & 0.04 & 0.002 & Baird et al. (1997); Alcorn (2003) \\
HCB & 0.9 & 0.108 & Alcorn (2003) \\
Iron sheet & 31.5 & 0.684 & Hammond and Jones (2008) \\
MDF & 11 & 0.161 & Hammond and Jones (2008) \\
Timber (m ${ }^{3}$ ) & 510 & 0.0 & Daily civil (2017) \\
Metal (openings) (structural steel) & 13.1 & 0.185 & Hammond and Jones (2008) \\
Aluminum & 192 & 8 & Alcorn (2003) \\
Ceramic floor and wall tile & 2.5 & 0.138 & Baird et al. (1997); Alcorn (2003) \\
Glass & 15.9 & 1.735 & Alcorn (2003) \\
Paint & 90.4 & 2.54 & Baird et al. (1997) \\
Gypsum plastering & 3.6 & 0.218 & Alcorn (2003) \\
Water (m ${ }^{3}$ ) & 13.038 & & Gerbens-Leenes (2016) \\
\hline
\end{tabular}


Table 8 Crops produced in 2014 and consumed land area for the production were adopted from CSA (2016)

\begin{tabular}{llll}
\hline & Area (ha) & Prod (qtl) & Prod (tone) \\
\hline Grain crops & $12,486,270.87$ & $266,828,807.04$ & $26,682,880.7$ \\
Cereals & $9,974,316.28$ & $231,287,970.83$ & $23,128,797.08$ \\
Pulses & $1,652,844.19$ & $27,692,743.11$ & $2,769,274.311$ \\
oilseeds & $859,110.39$ & $7,848,093.10$ & $784,809.31$ \\
Vegetables & $201,332.14$ & $7,444,468.39$ & $744,446.839$ \\
Root crops & $213,766.65$ & $39,985,663.02$ & $3,998,566.302$ \\
Fruit crops & $92,362.36$ & $6,797,428.30$ & $679,742.83$ \\
Chat & $251,381.15$ & $2,026,966.39$ & $202,696.639$ \\
Coffee & $653,909.76$ & $4,145,964.55$ & $414,596.455$ \\
Hops & $28,332.67$ & $371,622.33$ & $37,162.233$ \\
Sugarcane & $29,679.34$ & $13,769,813.48$ & $1,376,981.348$ \\
Sum & $26,443,305.80$ & $608,199,540.54$ & $60,819,954.05$ \\
National crop yield of $2014($ tone/ha) $=$ production/area & 2.3 ton/ha \\
\hline
\end{tabular}

\section{Publisher's Note}

Springer Nature remains neutral with regard to jurisdictional claims in published maps and institutional affiliations.

Received: 14 September 2018 Accepted: 9 January 2019

Published online: 18 January 2019

\section{References}

Airaksinen M, Matilainen P (2011) A carbon footprint of an office building. Energies 4:1197-1210. https://doi.org/10.3390/en4081197

Alcorn A (2003) Embodied energy and $\mathrm{CO}_{2}$ coefficients for New Zealand building materials. Centre for Building Performance Research, Victoria University of Wellington, Wellington

ASTU (2016) History of Adama City from its foundation to present (19192015). Adama Science and Technology University, Adama

Baird G, Alcorn A, Haslam P (1997) The energy embodied in building materials_-updated New Zealand coefficients and their significance. IPENZ Transactions 24 (1/CE)

Bastianoni S, Galli A, Niccolucci V, Pulselli RM (2006) The ecological footprint of building construction. The sustainable City IV: urban regeneration and sustainability. WIT Trans Ecol Environ 93:345-356

Borucke M, Moore D, Cranston G, Gracey K, Iha K, Larson J, Lazarus E et al (2013) Accounting for demand and supply of the biosphere's regenerative capacity: the National Footprint Accounts' underlying methodology and framework. Ecol Ind 24:518-533

Bulti DT, Sori ND (2017) Evaluating land-use plan using conformance-based approach in Adama City. Ethiopia. Spatial Inf Res. https://doi.org/10.1007/ s41324-017-0125-3

Chattefuee S, Hadi AS (2006) Regression analysis by example, 4th edn. John Wiley \& Sons Inc, Hoboken

CSA (2016) The Federal Democratic Republic of Ethiopia Central Statistical Agency Agricultural Sample Survey. Report On Area and Production of Major Crops Statistical Bulletin 1(1)

Daily civil (2017) Unit weight of building materials. http://www.dailycivil.com. Accessed 10 May 2018

Evans JD (1996) straightforward statistics for the behavioral science. Brooks/ Cole Publishing, Pacific Grove

Gelman A (2012) P values and statistical practice. epidemiology 24(1):69-72

Gerbens-Leenes PW (2016) Energy for freshwater supply, use, and disposal in the Netherlands: a case study of Dutch households. Int J Water Resour Dev 32(3):398-411
González-Vallejo PG, Marrero M, Guzman JS (2015) The ecological footprint of dwelling construction in Spain. Ecol Ind 52:75-84

Hamby DM (1994) A review of techniques for parameter sensitivity analysis of environmental models. Environ Monit Assess 32:135-154

Hammond GP, Jones CI (2008) Embodied energy and carbon in construction materials. Proc Inst Civil Eng Energy 161(2):87-98. https://doi. org/10.1680/ener.2008.161.2.87

Husain D, Prakash R (2018) Ecological footprint assessment and reduction of an academic building in Shahdol (India). European I Sustain Dev Res 2(4):42. https://doi.org/10.20897/ejosdr/3910

Kaufman L, Rousseeuw PJ (1990) Finding groups in data: an introduction to cluster analysis. John Wiley \& Son, Hoboken

Larralde L, González-Vallejo P, Marrero M (2014) Ecological footprint in of dwelling construction in Mexico. In: Proceedings of the II international and IV national congress on sustainable construction and eco-efficient solutions. p. 795-805

Lim YP, Yahya K, Aminudin E, Zakaria R, Haron Z, Mohamad Zin RM, Redzuan AAH (2017) Carbon footprint of construction using industrialized building System. Mater Sci Eng. https://doi.org/10.1088/1757-899x/271/1/012107

Lin D, Hanscom L, Martindill J, Borucke M, Cohen L, Galli A, Lazarus E, Zokai G, Iha K, Eaton D, Wackernagel M (2016) Working guidebook to the national footprint accounts, 2016th edn. Global Footprint Network, Oakland

Liu M, Zhang B, Ren J, Gu H,Yuan J (2018) Sustainability evaluation of the ecological footprint of rural residential houses with different materials. In: IOP conference series: materials science and engineering 394(032040). https //doi.org/10.1088/1757-899x/394/3/032040

Miglietta PP, Pastore S (2010) The ecological footprint: methodologies and applications. In: Conference paper. https://doi.org/10.13140 12.1.2853.4564

Monfreda C, Wackernagel M, Deumling D (2004) Establishing national natural capital accounts based on detailed ecological footprint and biological capacity accounts. Land Use Policy 21:231-246

Moore D, Larson J, Iha K, Gracey K, Wackernagel M (2013) Methodology for calculating the ecological footprint of California. Global Footprint Network

Nieminen P, Lehtiniemi H, Vähäkangas K, Huusko A, Rautio A (2013) Standardized regression coefficient as an effect size index in summarizing findings in epidemiological studies. Epidemiol Biostat Public Health. https://doi. org $/ 10.2427 / 8854$

Pearce AR, Vanegas JA (2002) Defining sustainability for built environment systems: an operational framework. Int J Environ Technol Manag. https:// doi.org/10.1504/ijetm.2002.000780

Rawlings JO, Pantula SG, Dickey DA (1998) Applied Regression Analysis: a research tool, 2nd edn. Springer-Verlag New York, Inc, New York

Saltelli A, Andres TH, Homma T (1993) Sensitivity analysis of model output: an investigation of new techniques. Comput Stat Data Anal 15:211-238

Saltelli A, Chan K, Scott EM (eds) (2000) Sensitivity analysis. John Wiley \& Sons, Chichester

Seltman HJ (2018) Experimental design and analysis. http://www.stat.cmu. edu/hseltman/309/Book/. Accessed 5 Sept 2018

Simion IM, Ghinea C, Maxineasa SG, Taranu N, Bonomi A, Gavrilescu A (2013) Ecological footprint applied in the assessment of construction and demolition waste integrated management. Environ Eng Manag J 12(4):779-788

Teng J, Wu X (2014) Eco-footprint-based life-cycle eco-efficiency assessment of building projects. Ecol Ind 39:160-168

Umar UA, Khamidi MF, Tukur H (2012) Sustainable building material for green building construction, conservation and refurbishing. In: Management in construction research association (MiCRA), postgraduate conference

UNEP (2007) Buildings and climate change: status, challenges and opportunities. United Nations Environment Program, Nairobi

Wackernagel M, Monfreda C, Moran D, Wermer P, Goldfinger S, Deumling D, Murray M (2005) National footprint and biocapacity accounts 2005: the underlying calculation method. Global Footprint Network, Oakland

Wiedmann T, Barrett J (2010) A review of the ecological footprint indicator-perceptions and methods. Sustainability 2:1645-1693. https://doi. org/10.3390/su2061645 
Wilson J (2005) Ecological footprints of canadian municipalities and regions. The FCM Ecological Footprint Analysis. Anielski Management Inc, Edmonton
Yilmaz M, Bakiş A (2015) Sustainability in construction sector. In: World conference on technology, innovation and entrepreneurship 195: 2253-62. https://doi.org/10.1016/j.sbspro.2015.06.312
Submit your manuscript to a SpringerOpen ${ }^{\odot}$ journal and benefit from:

- Convenient online submission

- Rigorous peer review

- Open access: articles freely available online

- High visibility within the field

- Retaining the copyright to your article

Submit your next manuscript at $\boldsymbol{\nabla}$ springeropen.com 